\title{
Characteristics, treatment patterns, and unmet needs of Japanese patients with atrial fibrillation
}

This article was published in the following Dove Press journal:

Research Reports in Clinical Cardiology

3 July 2013

Number of times this article has been viewed

\author{
Yukihiro Koretsune' \\ Bruno Rossi² \\ Kazuya Iwamoto ${ }^{3}$ \\ Edward CY Wang ${ }^{4}$ \\ Marco DiBonaventura ${ }^{5}$ \\ Jean-Baptiste Briere ${ }^{4}$ \\ 'Institute for Clinical Research, \\ Osaka National Hospital, Osaka, \\ Japan; ${ }^{2}$ Market Access, Bayer Yakuhin \\ Ltd., Osaka, Japan; ${ }^{3}$ Medical Affairs \\ Cardiovascular and Neurology, Bayer \\ Yakuhin Ltd., Osaka, Japan; ${ }^{4}$ Health \\ Economics and Outcomes Research, \\ Bayer Yakuhin Ltd., Osaka, Japan; \\ ${ }^{5}$ Health Outcomes Practice, Kantar \\ Health, New York, NY, USA
}

Background: Data on characteristics, comorbidities, health outcomes, and treatment patterns of patients with atrial fibrillation (AF) in Japan are scarce. The aim of this study was to address this gap in order to better understand the characteristics of Japanese AF patients.

Methods and results: The 2008-2010 Japan National Health and Wellness Survey data sets were used in this study $(\mathrm{N}=60,015)$. Demographics, health characteristics, stroke risk (using the $\mathrm{CHA}_{2} \mathrm{DS}_{2}$-VASc score), comorbidities, and health outcomes were all assessed. A total of 565 patients $(0.94 \%)$ self-reported a physician diagnosis of AF. Patients with AF reported a number of comorbidities, including another cardiovascular condition (87.08\%), a urological condition (67.79\%), and dyspepsia (37.35\%). Patients with AF also reported significantly worse health status and significantly more resource use than did controls. Based on the $\mathrm{CHA}_{2} \mathrm{DS}_{2}$-VASc score, most patients $(88.50 \%)$ were at either moderate or high risk, yet only $64.25 \%$ of patients were currently being treated. Among those not currently treated, $42.57 \%$ had discontinued previous treatment. Among those currently treated, over a third reported nonadherent behaviors.

Conclusion: Despite the disease burden and the high risk for a future stroke, not all patients are being treated according to guidelines. This treatment gap highlights the need for better therapeutic alternatives, in order to improve the management of patients with AF, in Japan.

Keywords: stroke risk, health status, adherence

\section{Background}

Atrial fibrillation (AF) is the most common sustained cardiac arrhythmia and is associated with substantial morbidity and mortality. ${ }^{1}$ In Japan, AF is estimated to be present in $0.65 \%$ of the population. ${ }^{2}$ As in the West, the prevalence of AF increases with age, with $4.43 \%$ Japanese men and $2.19 \%$ of women 80 years or older affected.

$\mathrm{AF}$ is independently associated with an increased risk of stroke, thromboembolism, and congestive heart failure. ${ }^{3}$ However, even before the onset of major sequelae, patients with AF may exhibit deficits in health status because of both symptom presentation (eg, palpitations, dizziness, breathlessness, exercise intolerance, and fatigue) and abnormal autonomic function itself. ${ }^{4,5}$ Compared with age-matched controls, van den Berg et al found patients with AF to exhibit significantly lower mean Short Form (SF)-36 ${ }^{\circledR}$ Health Survey (QualityMetric Inc, Lincoln, RI, USA) scores on all subscales except bodily pain. ${ }^{5}$ Kang and Bahler reported similar findings. ${ }^{6}$

The burden of AF also translates into substantial economic costs. In a systematic review, Wolowacz et al found direct costs ranging from $\$ 2000$ to $\$ 14,200$ per patientyear in the US, and $€ 450$ to $€ 3000$ in Europe. ${ }^{7}$ Hospitalizations accounted for the
Correspondence: Marco DiBonaventura Health Outcomes Practice, Kantar Health, II Madison Avenue, I2th Floor,

New York, NY 10010 USA

$\mathrm{Tel}+\mathrm{I} 2127063988$

Fax + I 2126477659

Email marco.dibonaventura@kantarhealth. com 
majority of these costs, which are comparable to those of other chronic conditions, such as type 2 diabetes mellitus. ${ }^{7}$ Indirect costs are also high in AF. Utilizing a large employee database, Rohrbacker et al found that employees with AF took significantly more sick leave and short-term disability than did healthy controls. ${ }^{8}$ Annual benefit costs paid to AF employees exceeded those paid to non-AF employees by a mean $\$ 3958$. $^{8}$

In order to limit cardiovascular complications, patients with AF are often administered antithrombotic medications. Unfortunately, antithrombotic agents increase the risk of bleeding; therefore, patients and their physicians must weigh the risks and benefits of managing AF with such treatments. ${ }^{9}$ Several risk scores (eg, $\mathrm{CHADS}_{2}, \mathrm{CHA}_{2} \mathrm{DS}_{2}-$ VASc, and HAS-BLED) have been proposed to inform physicians about which patients have greatest need for treatment. ${ }^{10}$ Nevertheless, research from other geographic areas suggests a substantial gap between risk status and appropriate treatment. ${ }^{11}$ Even among those treated, between $25 \%$ and $50 \%$ of patients were nonadherent, as defined by either medication possession ratios or proportion of days covered less than $0.80 .^{12}$

Despite existing literature on the burden, costs, and risk profile of patients with AF in the US and Europe, much less is known about patients with AF in Japan. Information on comorbidities, health outcomes, and treatment patterns of patients with AF in Japan is scarce. Given the aging population in Japan, AF will be an increasingly important condition from a public health perspective. No study, to our knowledge, has used a population-based health survey to understand the characteristics of patients with AF in Japan, and the current paper addresses this gap. Examining the similarities and differences with studies conducted in the West can help illuminate the unique considerations that are relevant to the Japanese patient when making treatment decisions.

\section{Methods}

\section{Data source}

The current study used data from the 2008, 2009, and 2010 Japan National Health and Wellness Surveys (NHWS) (Kantar Health, New York, NY, USA), an annual, crosssectional study of adults aged 18 years or older. The NHWS includes epidemiological data, treatment information, information on health risk behaviors, and health-related outcome data. Potential respondents to the NHWS are recruited through an existing web-based consumer panel. The consumer panel recruits its panel members through a variety of means, including opt-in emails, coregistration with panel partners, e-newsletter campaigns, Internet banner placements, and similar methods. All panelists must explicitly agree to be a panel member, register with the panel through a unique email address, and complete an in-depth demographic registration profile. The Japan NHWS was approved by an Institutional Review Board (Essex IRB, Inc., Lebanon, NJ, USA), and all respondents provided informed consent prior to participating. Modest compensation was provided for the respondents who completed the survey.

Using a stratified random sample framework (with quotas based on gender and age), the demographic composition of each year's Japan NHWS samples is comparable to that of the Japanese adult population. ${ }^{13}$ Because the NHWS uses random sampling with replacement each year, a subset of 2008 respondents also completed the survey in 2009 and 2010. Similarly, a subset who completed the survey in 2009 completed the survey in 2010 . In these instances, only the most recent data point for each respondent was included so as to avoid more than one set of data from the same respondent.

\section{Sample}

A total of 60,015 unique respondents completed the 2008, 2009, or 2010 Japan NHWS and were included in the analyses. Among them, 565 reported a physician diagnosis of AF.

\section{Measures}

\section{Sociodemographics}

Age (in intervals: 18 to 39 years, 40 to 49 years, 50 to 59 years, 60 to 69 years, 70 years and older), sex (male vs female), education (college educated vs less than college educated), employment (currently employed vs not currently employed), and annual household income (less than $¥ 3,000,000, ¥ 3,000,000$ to $¥ 4,999,999, ¥ 5,000,000$ to $¥ 7,999,999, ¥ 8,000,000$ or more, and decline to answer; these response choices approximately correspond to $\$ 30,000, \$ 30,000$ to $\$ 49,999, \$ 50,000$ to $\$ 79,999$, $\$ 80,000$ or more, and decline to answer) were included. Out-of-pocket costs for medications and physician visits were also assessed.

\section{Patient characteristics}

Smoking (currently smoke vs former smoker vs never smoked), alcohol use (currently drink vs do not currently drink), exercise (currently exercise vs do not currently exercise), weight (in kilograms), and the body mass index (BMI) (underweight or BMI $<18.5 \mathrm{~kg} / \mathrm{m}^{2}$, normal weight or BMI between 18.5 and $<25.0$, overweight or BMI between 
25.0 and $<30.0$, obese or BMI 30 or greater; decline to answer) were assessed for all respondents.

\section{Comorbidities}

The Charlson Comorbidity Index (CCI) ${ }^{14}$ which provides a summary score of the overall comorbidity burden of each respondent, was calculated based on self-reported comorbidities. A history of myocardial infarction, treatment for myocardial infarction, and diagnosed renal impairment were also assessed as individual conditions of interest. Comorbidities were also examined by the following clusters (either presence or absence of a condition in that cluster), as done in prior research: ${ }^{15}$ autoimmune, cancer, cardiovascular, dermatologic, dyspepsia, non-dyspepsia gastrointestinal, infectious, musculoskeletal, neurologic, ophthalmic, pain, psychological, respiratory, sleep, urologic, or other.

\section{AF history}

Diagnosis of AF, years diagnosed with AF, frequency of symptoms (one episode vs two or more episodes that last at least a week), self-reported AF symptom severity (in response to the question "How would you characterize your atrial fibrillation symptoms?," where possible answers were: mild, moderate, or severe), and stroke risk, as measured by both the CHADS 2 score and $\mathrm{CHA}_{2} \mathrm{DS}_{2}$-VASc score (low, moderate, or high risk) were all assessed. ${ }^{16}$

\section{Medication history}

Current antithrombotic agent (acetylsalicylic acid [ASA] only, ASA and warfarin, or warfarin only) and other AF medications (rate control or rhythm control) were included in the analyses. Among patients who were currently untreated, the proportion who had been on a treatment previously was reported. Among patients who had never been treated, the proportion who were never recommended a prescription medication for their AF by a physician was also reported. The total number of medications for their AF was included along with treatment satisfaction (only among medication users) and medication adherence (only among medication users). Adherence was assessed using the self-reported Morisky Medication Adherence Scale (MMAS), ${ }^{17}$ tailored specifically to AF. Adherence was categorized as completely adherent vs nonadherent.

\section{Health outcomes}

The Medical Outcomes Study 12-Item Short Form $\left(\mathrm{SF}-12 \mathrm{v} 2^{\circledR}\right.$ ) (QualityMetric Inc) Survey Instrument was used as a generic health status instrument. ${ }^{18}$ The Japan-specific version of this instrument was used. ${ }^{19,20}$ The physical component summary and mental component summary scores along with health utilities (SF-6D; QualityMetric Inc) were included in the analysis, with higher scores indicating better health status. Prior research has suggested that a 3-point and 0.03 difference in the summary scores and health utilities, respectively, corresponds to a clinically-meaningful change defined as "the smallest difference that patients perceive as beneficial and which would mandate, in the absence of troublesome side effects and excessive cost, a change in the patient's management." ${ }^{21,22}$ The Work Productivity and Activity Impairment (WPAI) questionnaire (Margaret Reilly Associates, Inc, New York, NY, USA) was used to assess absenteeism (the percentage of work time missed because of one's health in the past 7 days), presenteeism (the percentage of impairment experienced while at work in the past 7 days because of one's health), overall work productivity loss (an overall impairment estimate that is a combination of absenteeism and presenteeism), and activity impairment (the percentage of impairment in daily activities because of one's health in the past 7 days). ${ }^{23}$ Only respondents who reported being full-time or part-time employed provided data for absenteeism, presenteeism, and overall work impairment. All respondents provided data for activity impairment. The number of physician visits, Emergency Room (ER) visits, and hospitalizations in the previous 6 months were reported by all respondents.

\section{Statistical analysis \\ Description of Japanese AF patients}

Among all patients who reported a diagnosis of $\mathrm{AF}$, the distributions of the independent variables above were reported. Frequencies and percentages were reported for categorical variables, and means and standard deviations were reported for continuous outcomes. Comparisons between patients without AF were made on sociodemographics, health behaviors, and overall comorbidity burden, using Chi-square tests and $t$-tests for categorical and continuous variables, respectively.

\section{The burden of AF}

Adjusted differences, between those with and without AF, were assessed using general linear models (for health status) and generalized linear models (for work productivity and health care resource use). The latter models (specifying a negative binomial distribution and a log link function) were used to correctly handle the inherent skewness of those variables. All regression models were controlled for age, 
gender, education, household income, body mass index, exercise behavior, and the CCI. The a priori cutoff for statistical significance of predictors in the regression model was set at $P<0.05$.

\section{AF treatment patterns}

Current treatments and treatment history were reported descriptively. General linear models were conducted to predict medication adherence from medication satisfaction and number of medications, controlling for age, out-of-pocket costs (both physician and medication costs), use of a rhythm medication, and comorbidity burden. These variables were selected because they were the only variables in a bivariate analysis (not reported) to be significantly associated with adherence. The a priori cutoff for statistical significance of predictors in the regression model was set at $P<0.05$.

\section{Results}

\section{Patient characteristics}

Of the 60,015 respondents who completed the 2008, 2009, or 2010 Japan NHWS, a total of 565 respondents $(0.94 \%)$ reported being diagnosed with AF by a physician.
Compared with patients without AF, these patients were older ( 64.69 vs 49.15 years) and more likely to be male (83.54\% vs $53.51 \%$ ), to have a university education ( $67.08 \%$ vs $60.91 \%)$, to be unemployed ( $66.73 \%$ vs $42.42 \%$ ), and to have a lower household income $(52.92 \%$ vs $42.45 \%$ had an income of $<¥ 5,000,000$, which corresponds to approximately $\$ 50,000)$ (all $P<.0001$ ) (see Table 1). Patients with AF also reported significantly higher out-of-pocket costs for both physician visits and medications.

Patients with AF reported a significantly higher body weight (64.43 kg vs $60.26 \mathrm{~kg}$ ) and were more likely to be a former smoker (49.91\% vs $26.26 \%$ ) and to currently exercise $(58.94 \%$ vs $48.34 \%)$ (all $P<.0001)$ (see Table 2$)$. Patients with AF had a greater overall comorbidity burden (as assessed with the CCI). A total of $87.08 \%$ of patients with AF also reported another cardiovascular condition, such as hypertension (38.76\%), and $67.79 \%$ reported a urological condition, such as overactive bladder (28.72\%), 37.35\% reported dyspepsia, and $32.74 \%$ reported pain (see Figure 1). Additionally, 7.79\% of patients with AF reported a previous myocardial infarction, while $2.65 \%$ and $1.77 \%$ reported chronic kidney disease and moderate-to-severe renal disease, respectively.

Table I Sociodemographic differences between patients with atrial fibrillation and controls

\begin{tabular}{|c|c|c|c|c|c|}
\hline & \multicolumn{2}{|l|}{$\begin{array}{l}\text { AF } \\
N=565\end{array}$} & \multicolumn{2}{|c|}{$\begin{array}{l}\text { Control } \\
N=59,450\end{array}$} & \multirow[t]{2}{*}{$P$-value } \\
\hline & $\overline{\mathbf{N}}$ & $\%$ & $\overline{\mathbf{N}}$ & $\%$ & \\
\hline Age (years) & & & & & $<0.0001$ \\
\hline $18-39$ & 24 & 4.25 & 18819 & 31.66 & \\
\hline $40-49$ & 32 & 5.66 & 9542 & 16.05 & \\
\hline $50-59$ & 74 & 13.10 & 12713 & 21.38 & \\
\hline $60-69$ & 211 & 37.35 & 12453 & 20.95 & \\
\hline 70 and older & 224 & 39.65 & 5923 & 9.96 & \\
\hline Gender & & & & & $<0.0001$ \\
\hline Male & 472 & 83.54 & 31811 & 53.51 & \\
\hline Female & 93 & 16.46 & 27639 & 46.49 & \\
\hline Education & & & & & 0.002 \\
\hline Less than university education & 186 & 32.92 & 23238 & 39.09 & \\
\hline University education & 379 & 67.08 & 36212 & 60.91 & \\
\hline Employment & & & & & $<0.0001$ \\
\hline Unemployed & 377 & 66.73 & 25219 & 42.42 & \\
\hline Currently employed & 188 & 33.27 & 34231 & 57.58 & \\
\hline Annual household income & & & & & $<0.0001$ \\
\hline$<¥ 3$ million (approximately $<\$ 30,000$ ) & 99 & 17.52 & 9791 & 16.47 & \\
\hline$¥ 3$ to $<¥ 5$ million (approximately $\$ 30,000$ to $<\$ 50,000$ ) & 200 & 35.40 & 15445 & 25.98 & \\
\hline$¥ 5$ to $<¥ 8$ million (approximately $\$ 50,000$ to $<\$ 80,000$ ) & 124 & 21.95 & 15156 & 25.49 & \\
\hline$¥ 8$ million or more (approximately $\$ 80,000$ or more) & 94 & 16.64 & 13393 & 22.53 & \\
\hline Decline to answer & 48 & 8.50 & 5665 & 9.53 & \\
\hline Out-of-pocket costs (physician visits) (mean, SD)* & $¥ 6215.77$ & $¥|3| 4 \mid .83$ & $¥ 2989.33$ & $¥ 7594.58$ & $<0.0001$ \\
\hline Out of pocket costs (medications) (mean, SD) & $¥ 7972.22$ & $¥|47| 6.31$ & $¥ 3877.52$ & $¥ 8699.99$ & $<0.0001$ \\
\hline
\end{tabular}

Notes: *Out of pocket costs for physician visits were not asked in all years of the NHWS (Kantar Health, New York, NY, USA) ( $\mathrm{n}=336,34,399$ for AF and controls, respectively). Within-variable categories may not sum to exactly $100 \%$ due to rounding.

Abbreviations: AF, atrial fibrillation; NHWS, National Health and Wellness Survey; SD, standard deviation. 
Table 2 Health behavior differences between patients with atrial fibrillation and controls

\begin{tabular}{|c|c|c|c|c|c|}
\hline & \multicolumn{2}{|c|}{$\begin{array}{l}A F \\
N=565\end{array}$} & \multicolumn{2}{|c|}{$\begin{array}{l}\text { Control } \\
N=59,450\end{array}$} & \multirow[t]{2}{*}{$P$-value } \\
\hline & $\mathbf{N}$ & $\%$ & $\mathbf{N}$ & $\%$ & \\
\hline Body mass index & & & & & $<0.0001$ \\
\hline Missing & 1 & 0.18 & 1780 & 2.99 & \\
\hline Underweight & 36 & 6.37 & 8056 & 13.55 & \\
\hline Normal & 390 & 69.03 & 38791 & 65.25 & \\
\hline Overweight & 123 & 21.77 & 9281 & $15.6 \mathrm{I}$ & \\
\hline Obese & 15 & 2.65 & 1542 & 2.59 & \\
\hline Weight (kg) (mean, SD) & 64.43 & 10.94 & 60.26 & 12.09 & $<0.0001$ \\
\hline Smoking status & & & & & $<0.0001$ \\
\hline Never smoked & 175 & 30.97 & 29651 & 49.88 & \\
\hline Former smoker & 282 & 49.91 & 15609 & 26.26 & \\
\hline Current smoker & 108 & 19.12 & 14190 & 23.87 & \\
\hline Alcohol use & & & & & 0.1672 \\
\hline Do not drink & 134 & 23.72 & 15579 & 26.21 & \\
\hline Currently drink & 431 & 76.28 & 43871 & 73.79 & \\
\hline Exercise behavior & & & & & $<0.0001$ \\
\hline Do not exercise & 232 & 41.06 & 30709 & 51.66 & \\
\hline Currently exercise & 333 & 58.94 & $2874 I$ & 48.34 & \\
\hline Charlson Comorbidity & 0.77 & 2.98 & 0.13 & 0.43 & $<0.0001$ \\
\hline Index ${ }^{14}$ (mean, SD) & & & & & \\
\hline
\end{tabular}

Note: Within-variable categories may not sum to exactly $100 \%$, due to rounding. Abbreviations: AF, atrial fibrillation; SD, standard deviation.

Patients with AF had been diagnosed a mean of 10.35 years previously, and most patients reported their symptoms severity as mild (56.99\%) (see Table 3 ). The majority $(53.10 \%)$ of patients were at high risk for a future stroke, based on the $\mathrm{CHA}_{2} \mathrm{DS}_{2}$-VASc score (a score of 2 or higher), as compared with $19.12 \%$, based on the $\mathrm{CHADS}_{2}$ score (a score of 2 or higher) (see Figure 2). Indeed, the $\mathrm{CHA}_{2} \mathrm{DS}_{2}-$ VASc score is a refinement of the $\mathrm{CHADS}_{2}$ score, which incorporates more risk factors. In our sample, treatment with anticoagulation varied from $16.92 \%$ to $31.50 \%$ to $34.00 \%$ for those at low to moderate to high risk, respectively, based on the $\mathrm{CHA}_{2} \mathrm{DS}_{2}-\mathrm{VASc}$.

\section{Burden of those with $A F$}

After adjusting for sociodemographics, health history, and comorbidities, patients with AF reported a significantly and clinically-meaningful burden with respect to both physical component summary scores $(46.65$ vs 50.54$)(P<0.0001)$ and health utilities $(0.73$ vs 0.76$)(P=0.0005)$ (see Table 4$)$. Those results contrast with the results of Table 3, where $56.99 \%$ of patients with AF reported their symptoms to be mild. This gap suggests that patients with AF downplay their symptoms, and it emphasizes the importance of proper explanation of the potential complications of the disease. No differences were observed with respect to the mental component summary scores.

Although the number of ER visits was not significantly different between the two groups, patients with AF did report significantly more physician visits (8.45 vs 5.15 ) $(P<0.0001)$ and hospitalizations than did controls (1.33 vs 0.49$)(P=0.0052)$. Patients with AF also reported significantly more activity impairment, relative to controls (26.35\% vs $17.59 \%)(P<.0001)$.

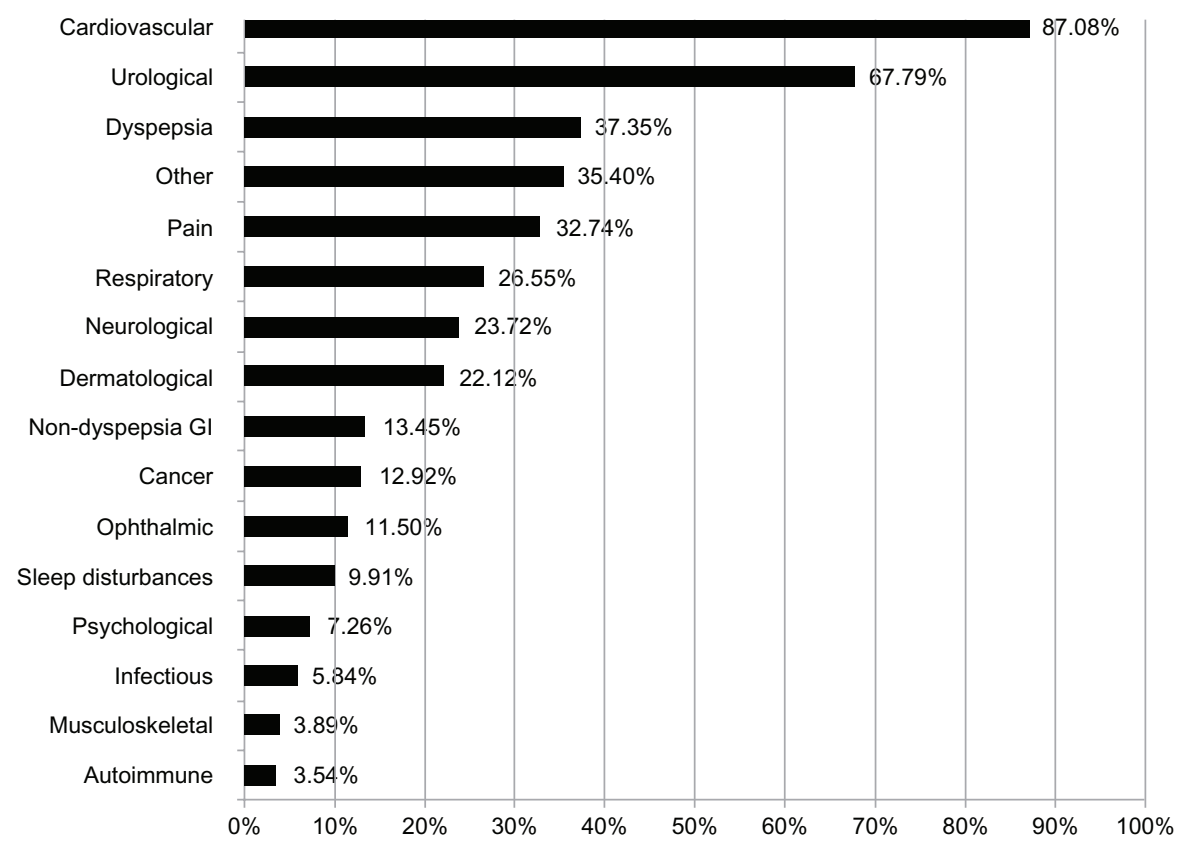

Figure I Prevalence of comorbidities among patients with atrial fibrillation. Abbreviation: $\mathrm{Gl}$, gastrointestinal. 
Table 3 Disease history of patients with atrial fibrillation

\begin{tabular}{lll}
\hline & AF & \\
\cline { 2 - 3 } & $\mathbf{N}=\mathbf{5 6 5}$ & $\%$ \\
\cline { 2 - 3 } & $\mathbf{N}$ & 10.60 \\
\hline $\begin{array}{l}\text { Years diagnosed (mean, SD) } \\
\text { Severity }\end{array}$ & 10.35 & \\
$\quad$ Mild & 322 & 56.99 \\
$\quad$ Moderate & 186 & 32.92 \\
Severe & 57 & 10.09 \\
Location of diagnosis & & \\
$\quad$ Unknown & 24 & 4.25 \\
$\quad$ Hospital & 415 & 73.45 \\
$\quad$ Physician's office & 104 & 18.41 \\
$\quad$ Other & 22 & 3.89 \\
Use a prescription medication for AF & & \\
$\quad$ Yes & 363 & 64.25 \\
$\quad$ No & 202 & 35.75 \\
Frequency of AF episodes that last a week or more & \\
$\quad$ One episode & 264 & 48.09 \\
Two or more episodes & 285 & 51.91 \\
\hline
\end{tabular}

Abbreviations: $\mathrm{AF}$, atrial fibrillation; SD, standard deviation.

\section{Treatment patterns}

A total of $35.75 \%$ of patients with AF were "currently untreated" with any prescription treatment for their condition; among them, $42.57 \%$ had discontinued treatment, though the reasons for discontinuation are not known (see Figure 3). Among patients who "have never been treated," the majority $(83.96 \%)$ stated that treatment had never been recommended to them. Among those patients who never used treatment nor had treatment recommended, the risk for stroke was just as high as among the overall AF population (55.06\% were at high risk, according to the $\mathrm{CHA}_{2} \mathrm{DS}_{2}-\mathrm{VASc}$ score).

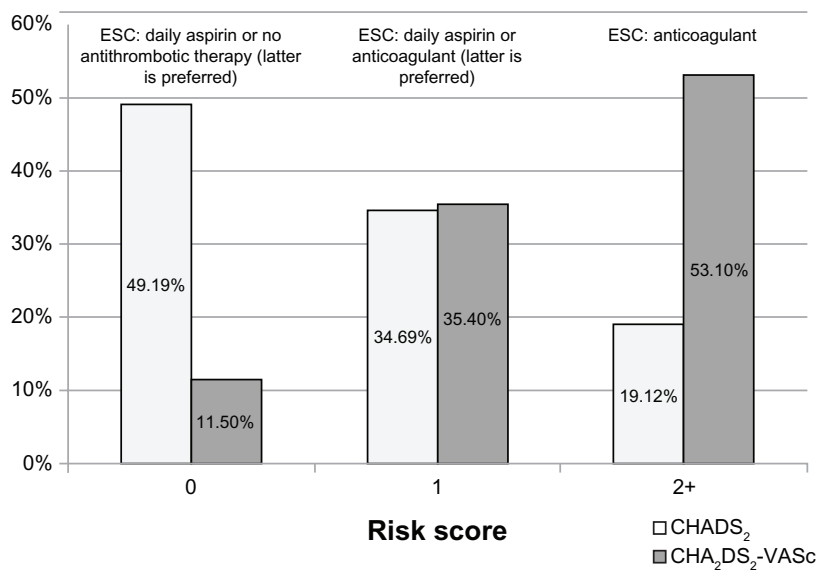

Figure $2 \mathrm{CHADS}_{2}$ and $\mathrm{CHA}_{2} \mathrm{DS}_{2}-\mathrm{VASc}$ scores $^{10}$ distribution among Japanese AF patients.

Notes: ESC represents European Society of Cardiology guidelines, ${ }^{15}$ which provide treatment recommendations based on these risk algorithms.

Abbreviations: AF, atrial fibrillation; ESC, European Society of Cardiology.
Table 4 Summary of the adjusted means for those with and without AF

\begin{tabular}{|c|c|c|c|}
\hline & $\begin{array}{l}\text { AF } \\
N=565\end{array}$ & $\begin{array}{l}\text { Control } \\
N=\mathbf{5 9 , 4 5 0}\end{array}$ & $P$ \\
\hline $\begin{array}{l}\text { Mental component } \\
\text { summary score }\end{array}$ & 46.565 & 47.213 & 0.1207 \\
\hline $\begin{array}{l}\text { Physical component } \\
\text { summary score }\end{array}$ & 46.649 & 50.537 & $<0.0001$ \\
\hline Health utility scores & 0.727 & 0.757 & 0.0005 \\
\hline Absenteeism \% & 3.545 & 2.995 & $0.584 I$ \\
\hline Presenteeism \% & 18.705 & 15.262 & 0.0527 \\
\hline Overall work impairment \% & 20.598 & 17.000 & 0.0691 \\
\hline Activity impairment \% & 26.354 & 17.592 & $<0.0001$ \\
\hline $\begin{array}{l}\text { Number of physician visits } \\
\text { (past } 6 \text { months) }\end{array}$ & 8.447 & 5.151 & $<0.0001$ \\
\hline $\begin{array}{l}\text { Number of ER visits (past } 6 \\
\text { months) }\end{array}$ & 0.155 & 0.105 & 0.2819 \\
\hline $\begin{array}{l}\text { Number of hospitalizations } \\
\text { (past } 6 \text { months) }\end{array}$ & 1.325 & 0.486 & 0.0052 \\
\hline
\end{tabular}

Of those who were currently treated, $48.48 \%$ were using warfarin, $40.50 \%$ were using a rate control medication, $21.49 \%$ were using a rhythm control medication, and $9.36 \%$ were using aspirin, (the percentages totaled to more than $100 \%$ due to medication overlap). Over a third (36.59\%) of patients who were currently treated by any prescription medication for AF reported some level of nonadherence, based on the MMAS. Even after adjusting for age, out-ofpocket costs, use of a rhythm medication, and the comorbidity burden of the patient (other factors that were significantly associated with adherence), the number of medications $(\mathrm{b}=0.13)(P=0.003)$ and treatment satisfaction $(\mathrm{b}=-0.12)$ $(P=0.03)$ were significantly associated with adherence. Specifically, a reduced number of AF medications and increased treatment satisfaction were significantly associated with greater adherence (see Table 5).

\section{Discussion}

Similar to those in other geographic areas, patients with AF in Japan were older and carried a greater comorbidity burden than did patients without AF. ${ }^{11,14}$ Through a combination of their behaviors (eg, smoking) and health characteristics, most patients were at moderate-to-high risk for a future stroke.

However, the Japanese AF population differs from that in other regions, with a more dramatic gender split and a lower body weight. Research in Europe and the United States has reported approximately $60 \%$ of patients with AF are male, ${ }^{11,15}$ whereas our current study reported over $80 \%$. With $69 \%$ of patients being male, the Japanese J-RHYTHM registry ${ }^{24}$ has provided further evidence supporting the 


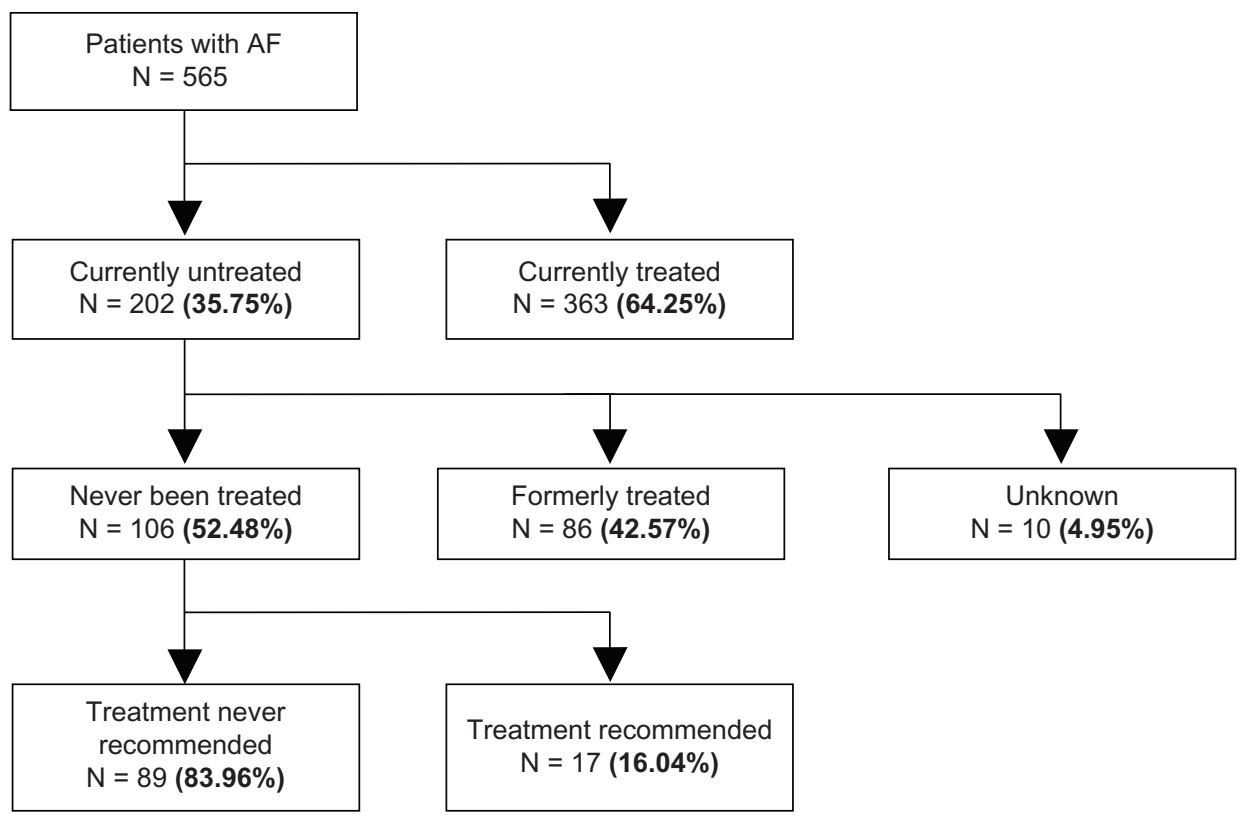

Figure 3 Overall treatment history of patients with atrial fibrillation.

Abbreviation: AF, atrial fibrillation.

gender split difference. Of note, the J-RHYTHM registry included only patients treated by specialists, whereas the NHWS included a broader patient population. It remains unclear the extent to which this discrepancy is reflective of the underdiagnosis of females or the natural course of AF, in Japan. Perhaps women in Japan disproportionately have fewer AF-related risk factors compared with women in other regions. Further research would be necessary to explore this hypothesis. The body weight for patients with $\mathrm{AF}$ in the current study was similar to the body weight found among patients in a related Japanese clinical trial (J-ROCKET AF trial $)^{25}$ as well as in the Japanese subanalysis of international trials (RELY, ARISTOTLE-J). ${ }^{26,27}$ These figures were roughly

Table 5 General linear model results predicting nonadherence among patients using a medication for their atrial fibrillation

\begin{tabular}{|c|c|c|c|c|}
\hline Variable & b & $95 \%$ LCL & $95 \%$ UCL & $P$ \\
\hline Intercept & 0.869 & -0.384 & 2.123 & 0.172 \\
\hline Age & -0.002 & -0.018 & 0.014 & 0.8245 \\
\hline $\begin{array}{l}\text { Out-of-pocket costs } \\
\text { (physician) }\end{array}$ & $0.000^{*}$ & 0.000 & 0.000 & $0.006 \mathrm{I}$ \\
\hline $\begin{array}{l}\text { Out-of-pocket costs } \\
\text { (medication) }\end{array}$ & $-0.000 *$ & 0.000 & 0.000 & 0.0366 \\
\hline Use of a rhythm medication & 0.359 & 0.036 & 0.682 & 0.0295 \\
\hline Comorbidity burden $(\mathrm{CCl})^{14}$ & $-0.05 I$ & -0.122 & 0.020 & 0.1546 \\
\hline Number of AF medications & 0.131 & 0.045 & 0.217 & 0.0031 \\
\hline Treatment satisfaction & -0.118 & -0.225 & -0.011 & 0.0316 \\
\hline
\end{tabular}

Notes: *The precise values for physician and medication out-of-pocket costs were 0.0000334180 and -0.0000188849 , respectively.

Abbreviations: b, regression coefficient; CCl, Charlson Comorbidity Index $\mathrm{LCL}$, lower confidence limit; UCL, upper confidence limit.
$20 \%$ lower than what was reported in international (ie, nonJapanese) trials (ROCKET AF, RELY, ARISTOTLE). ${ }^{27-30}$ These results suggest that, in addition to other consideration, such as the $\mathrm{CHA}_{2} \mathrm{DS}_{2}$-VASc score and comorbidities, body weight is an important factor to consider for proper treatment of Japanese patients with AF.

Similar to research findings from other regions, ${ }^{5,6}$ our results suggest that $\mathrm{AF}$ is significantly associated with worse health status, even after adjusting for a number of confounding variables. Our results also suggest a significantly greater economic burden from a societal perspective, as health care resource use was significantly higher among those with AF. Lastly, our results suggest that AF is significantly associated with greater activity impairment. Overall, these results suggest a significant burden among patients with AF, higher than the burden observed for controlled asthma, with regards to the physical component of quality of life and the number of hospitalizations. ${ }^{31}$

Despite that the majority of Japanese patients with AF are at high risk for a future stroke, many remain untreated. Interestingly, among untreated patients, more than $40 \%$ reported a previous treatment, and among treated patients, over a third reported nonadherent behaviors. Several factors were associated with nonadherence, including out-ofpocket costs for physician visits, which likely served as a proxy measure for comorbidities and the use of a rhythm medication. Interestingly, out-of-pocket costs for medications were associated with less nonadherence. Although the nature 
of this relationship is unclear, it is possible that patients in Japan may place greater value on medications that cost more and may be less likely to be nonadherent with their use. Both higher treatment satisfaction and fewer medications were associated with improved adherence. This highlights the need for better treatment alternatives.

\section{Limitations}

The limitations of this research should be noted. First, all data from the NHWS were self-reported, and no clinical verification of diagnoses or treatments were available. This is particularly relevant for the diagnosis of AF. Some patients may have erroneously reported that they have been diagnosed with AF, when they have not, and others may have failed to report a diagnosis they had actually received. These misclassifications would have introduced additional measurement error and would have weakened the relationships observed here, assuming the error was truly random. This is clearly a limitation, though patientreported data does provide the advantage of assessing information that can only reliably be obtained from the patients themselves (eg, health-related quality of life, satisfaction, etc). Also, the NHWS did not assess specific clinical subtypes of AF, and this would be a topic for future research. Finally, it is possible that the sample of patients with AF in the current study differs from the AF population in Japan. However, NHWS is nationally representative of the Japanese population with respect to age and gender, ${ }^{13}$ and the demographic characteristics of the sample of AF patients matched a previous publication by Inoue et al. ${ }^{2}$

\section{Conclusion}

Patients in Japan are generally similar to those in other geographic areas, with respect to age, comorbidity, risk status, and disease burden, though they differ markedly in the distribution of gender and body weight, emphasizing the importance of region-specific data to inform treatment decision making. In Japan, patients with AF reported significant decrements with respect to health-related quality of life, impairment in daily activities, and health care resource utilization. As a result, proper management of these patients is especially important. Most patients are at an elevated risk for a future stroke, yet only a minority of them receive adequate treatment, suggesting greater adherence to established guidelines is necessary. Among those who receive adequate treatment, medication adherence is a common problem, with nonadherence being associated with the number of medications and patient satisfaction with treatment. These findings suggest clinicians should be cognizant of the effect of pill burden and patient preference and how these may influence adherence.

\section{Acknowledgments}

The authors would like to thank Jan-Samuel Wagner for his assistance with the literature review.

\section{Disclosure}

The National Health and Wellness Survey (NHWS) is fielded by Kantar Health. Bayer Yakuhin Ltd purchased access to the NHWS data and funded the analysis and preparation of this manuscript. Dr Koretsune was a paid consultant to Bayer Yakuhin Ltd, for critical discussions on study analysis, study interpretation, and clinical insights. Dr DiBonaventura is an employee of Kantar Health. Mr Rossi and Dr Wang are employees of Bayer Yakuhin Ltd. Dr Iwamoto and Dr Briere were employees of Bayer Yakuhin Ltd. at the time of study. Mr Wagner (mentioned in the acknowledgments section) was a paid consultant to Kantar Health for assistance with the literature review. The authors report no other conflicts of interest.

\section{References}

1. Peters NS, Schilling RJ, Kanagaratnam P, Markides V. Atrial fibrillation: strategies to control, combat, and cure. Lancet. 2002;359(9306): 593-603.

2. Inoue H, Fujiki A, Origasa $H$, et al. Prevalence of atrial fibrillation in the general population of Japan: an analysis based on periodic health examination. Int J Cardiol. 2009;137(2):102-107.

3. Lip GY, Tse HF. Management of atrial fibrillation. Lancet. 2007; 370(9587):604-618.

4. Smith D, Lip GY, Lane DA. Impact of symptom control on health-related quality of life in atrial fibrillation patients: the psychologist's viewpoint. Europace. 2010;12(5):608-610.

5. van den Berg MP, Hassink RJ, Tuinenburg AE, et al. Quality of life in patients with paroxysmal atrial fibrillation and its predictors: importance of the autonomic nervous system. Eur Heart J. 2001;22(3): 247-253.

6. Kang Y, Bahler R. Health-related quality of life in patients newly diagnosed with atrial fibrillation. Eur J Cardiovasc Nurs. 2004;3(1): 71-76.

7. Wolowacz SE, Samuel M, Brennan VK, Jasso-Mosqueda JG, Van Gelder IC. The cost of illness of atrial fibrillation: a systematic review of the recent literature. Europace. 2011;13(10):1375-1385.

8. Rohrbacker NJ, Kleinman NL, White SA, March JL, Reynolds MR. The burden of atrial fibrillation and other cardiac arrhythmias in an employed population: associated costs, absences, and objective productivity loss. J Occup Environ Med. 2010;52(4):383-391.

9. Hughes M, Lip GY; Guideline Development Group for the NICE national clinical guideline for management of atrial fibrillation in primary and secondary care. Risk factors for anticoagulation-related bleeding complications in patients with atrial fibrillation: a systematic review. QJM. 2007;100(10):599-607.

10. Lip GY, Tse HF, Lane DA. Atrial fibrillation. Lancet. 2012;379(9816): 648-661.

11. Gupta S, Goren A, Freedman D. Risk of stroke and preventative steps among patients diagnosed with atrial fibrillation in Europe. Presented at the International Society of Pharmacoeconomics and Outcomes Research Annual European Meeting; November 6-9, 2010; Prague, Czech Republic. Value Health. 2010;13(7):A345. 
12. Laliberté F, Nelson WW, Lefebvre P, Schein JR, Rondeau-Leclaire J, Duh MS. Impact of daily dosing frequency on adherence to chronic medications nonvalvular atrial fibrillation patients. Adv Ther. 2012; 29(8):675-690.

13. Liu GG, DiBonaventura M, Yuan Y, et al. The burden of illness for patients with viral hepatitis C: evidence from a national survey in Japan. Value Health. 2012;15(Suppl 1):S65-S71.

14. Charlson ME, Pompei P, Ales KL, MacKenzie CR. A new method of classifying prognostic comorbidity in longitudinal studies: development and validation. J Chronic Dis. 1987;40(5):373-383.

15. LaMori J, Gross H, Patel A, Crain M, et al. Burden of comorbidities among patients with atrial fibrillation. Presented at the International Society of Pharmacoeconomics and Outcomes Research Annual International Meeting; May 21-25, 2011; Baltimore, MD, USA.

16. European Heart Rhythm Association; European Association for CardioThoracic Surgery; Camm AJ, Kirchof P, Lip GY, et al. Guidelines for the management of atrial fibrillation: Task Force for the Management of Atrial Fibrillation of the European Society of Cardiology (ESC) Euro Heart J. 2010;31(19):2369-2429.

17. Morisky DE, Green LW, Levine DM. Concurrent and predictive validity of a self-reported measure of medication adherence. Med Care. 1986;24(1):67-74.

18. Ware J Jr, Kosinski M, Keller SD. A 12-item Short-Form Health Survey: construction of scales and preliminary tests of reliability and validity. Med Care. 1996;34(3):220-233.

19. Fukuhara S, Bito S, Green J, Hsiao A, Kurokawa K. Translation, adaptation, and validation of the SF-36 Health Survey for use in Japan. J Clin Epidemiol. 1998;51(11):1037-1044.

20. Fukuhara S, Ware JE Jr, Kosinski M, Wada S, Gandek B. Psychometric and clinical tests of validity of the Japanese SF-36 Health Survey. J Clin Epidemiol. 1998;51(11):1045-1053.

21. Walters SJ, Brazier JE. What is the relationship between the minimally important difference and health state utility values? The case of the SF-6D. Health Qual Life Outcomes. 2003;1:4
22. Hays RD, Morales LS. The RAND-36 measure of health-related quality of life. Ann Med. 2001;33(5):350-357.

23. Reilly MC, Zbrozek AS, Dukes EM. The validity and reproducibility of a work productivity and activity impairment instrument. Pharmacoeconomics. 1993;4(5):353-365.

24. Ogawa S, Yamashita T, Yamazaki T, et al; J-RHYTHM Investigators. Optimal treatment strategy for patients with paroxysmal atrial fibrillation: J-RHYTHM Study. Circ J. 2009;73(2):242-248.

25. Hori M, Matsumoto M, Tanahashi N, et al; J-ROCKET AF study investigators. Rivaroxaban vs warfarin in Japanese patients with atrial fibrillation - the J-ROCKET AF study. Circ J. 2012;76(9):2104-2111.

26. Pharmaceutials and Medical Devices Agency (PMDA). [Dabigatran] [briefing document]. Tokyo: PMDA; 2011. Japanese. Available from: http://www.info.pmda.go.jp/shinyaku/P201100019/530353000_2230 0AMX00433000_A100_1.pdf. Accessed July 13, 2012.

27. Ogawa S, Shinohara Y, Kanmuri K. Safety and efficacy of the oral direct Factor Xa inhibitor apixaban in Japanese patients with non-valvular atrial fibrillation. -The ARISTOTLE-J study-. Circ J. 2011;75(8): 1852-1859.

28. Patel MR, Mahaffey KW, Garg J, et al; ROCKET AF Investigators. Rivaroxaban versus warfarin in nonvalvular atrial fibrillation. $N$ Engl J Med. 2011;8;365(10):883-891.

29. Connolly SJ, Ezekowitz MD, Yusuf S, et al; RE-LY Steering Committee and Investigators. Dabigatran versus warfarin in patients with atrial fibrillation. $N$ Engl J Med. 2009;361(12):1139-1151.

30. Granger CB, Alexander JH, McMurray JJ, et al; ARISTOTLE Committees and Investigators. Apixaban versus warfarin in patients with atrial fibrillation. $N$ Engl J Med. 2011;365(11):981-992.

31. DiBonaventura MD, Arakawa I, Fukuda T, Nagaeu T, Wagner JS, Stankus A. The effect of uncontrolled asthma on health-related quality of life and resource use in Japan and the United States. Presented at the International Society of Pharmacoeconomics and Outcomes Research Biannual Asia-Pacific Meeting; September 5-7, 2010; Phuket, Thailand Value Health. 2010;13(7):A561
Research Reports in Clinical Cardiology

\section{Publish your work in this journal}

Research Reports in Clinical Cardiology is an international, peerreviewed, open access journal publishing original research, reports, editorials, reviews and commentaries on all areas of cardiology in the clinic and laboratory. The manuscript management system is completely online and includes a very quick and fair peer-review system.

\section{Dovepress}

Visit http://www.dovepress.com/testimonials.php to read real quotes from published authors. 